\title{
RECENT TRENDS IN ANTIMICROBIAL RESISTANCE AMONG StREPTOCOCCUS PNEUMONIAE AND STAPHYLOCOCCUS AUREUS ISOLATES: THE FRENCH EXPERIENCE
}

\author{
Anonymous (b.coignard@invs.sante.fr) ${ }^{1}$ \\ 1. Contributors are listed at the end of the paper. The indicated corresponding author summarised the data and coordinated \\ the editorial process.
}

\begin{abstract}
In France, the overall proportion of penicillin-non-susceptible Streptococcus pneumoniae has decreased from 53\% in 2002 to $38 \%$ in 2006, and the proportion of methicillin-resistant Staphylococcus aureus from $33 \%$ in 2001 to $26 \%$ in 2007 . Although the rates remain very high compared to northern European countries, these trends suggest that the prevention efforts implemented since 2000 through two national programmes (the national plan for preserving the efficacy of antibiotics and the national infection control programme) and updated recommendations for pneumococcal vaccination are successful.
\end{abstract}

\section{Introduction}

Antimicrobial resistance is a multifaceted threat of global concern in the European Union. In this article, we illustrate results and efforts to counteract its spread in France through two microorganisms, Streptococcus pneumoniae and Staphylococcus aureus, that are frequently isolated from community-acquired or hospital-acquired infections, respectively*. The proportion of resistance in these species is a good indicator of the evolution of antimicrobial resistance in France and these bacteria are key targets of two national programmes: the national plan for preserving the efficacy of antibiotics [1] and the national programme for infection control [2]. Quantitative targets were included in these programmes in 2004 [3], aiming to reduce, by 2008 , the proportion of penicillin-non-susceptible strains among $S$. pneumoniae isolates to under $30 \%$ and the proportion of methicillin-resistant (MRSA) strains among $S$. aureus isolates to under $25 \%$.

\section{Streptococcus pneumonioe resistance trends}

\section{Data sources}

Antimicrobial susceptibility in S. pneumoniae is studied by a group of 22 regional laboratory networks (Observatoires Régionaux du Pneumocoque), covering the 22 French metropolitan regions (excluding overseas regions) and coordinated by the French national reference centre for S. pneumoniae (CNRP). The CNRP collects all blood or cerebrospinal fluid (CSF) isolates from children under the age of 15 years, all CSF isolates from adults, and a selection of strains isolated from adults with respiratory tract infections (respiratory or blood isolates) or from children with acute otitis media [4].

Since 2001, susceptibility testing results for invasive isolates (blood or CSF) have been submitted to the European Antimicrobial
Resistance Surveillance System (EARSS; http://www.rivm.nl/earss/). All laboratories use agar dilution and recommendations from the Antibiogram Committee of the French Society for Microbiology (CA-SFM, http://www.sfm.asso.fr/) for antimicrobial susceptibility testing and breakpoints. However, yearly data submitted by France to EARSS only included the first six months of a given year due to time constraints in the European data collection process; the data presented in the following include all strains received annually by the CNRP.

\section{Results}

Participation of laboratories has been stable since 2001. In 2006, for instance, the CNRP collected 1,411 strains from 406 private or public microbiological laboratories that provide support for 444 healthcare facilities covering $61.4 \%$ of admissions to French medical wards. Among those strains, 857 (61\%) were isolated from invasive infections (blood or CSF) and 554 (39\%) were isolated from respiratory tract infections.

Overall, the proportion of penicillin-non-susceptible S. pneumoniae (PNSP) was negligible before 1987 and then increased regularly every year, up to $53 \%$ in 2002 (48\% and $46 \%$ of blood and CSF isolates, respectively). Between 2003 and 2005, the proportion of PNSP decreased, and remained stable (38\%) in 2006 (34\% for blood and CSF isolates) (Figure 1) [4].

Among invasive S. pneumoniae isolates, the overall proportion of PNSP decreased from $47 \%$ in 2001 to $34 \%$ in 2006 . This corresponded to a decrease from $51 \%$ to less than $32 \%$ in children under the age of 15 years, and from $45 \%$ to $35 \%$ in adults (Table 1 ). A sharp reduction was noted in the proportion of PNSP (from $67 \%$ to $27 \%$ ) among CSF isolates from children under the age of two years. The change in blood isolates in the same age group was less pronounced, with the proportion of PSNP remaining at or above $40 \%$ throughout this period and even increasing in 2006.

\section{Discussion: prevention and control activities}

The observed decrease in PNSP started after the implementation in November 2001 by French public health authorities of the first national plan for preserving the efficacy of antibiotics (Figure 1). Two studies helped to define actions of this plan targeting the community: In 2000, a controlled, population-based trial was conducted in three French regions and demonstrated that intensive 
educational strategies aimed at optimising antibiotic use could significantly reduce the rate of PNSP colonisation [5]. In 2002, a study conducted by the French National Insurance Fund for Salaried Workers (CNAMTS) showed that both physicians and patients had little knowledge on antibiotics, resulting in poor antibiotic practices.

A multifaceted programme was then initiated by CNAMTS to avoid inappropriate antibiotic use in outpatients. The "Antibiotics aren't automatic!" campaign (http://www.antibiotiquespasautomatiques. $\mathrm{com} /$ ) aimed at increasing awareness of physicians as well as the public on good antibiotic practices. Using humoristic television commercials, it targeted specific populations likely to ask for antibiotics (young mothers, young workers, the elderly) and

\section{F I G U R E 1}

Proportion of penicillin non-susceptible $S$. pneumoniae among all strains studied by CNRP, France, 1984 to $2006(n=50,300)$

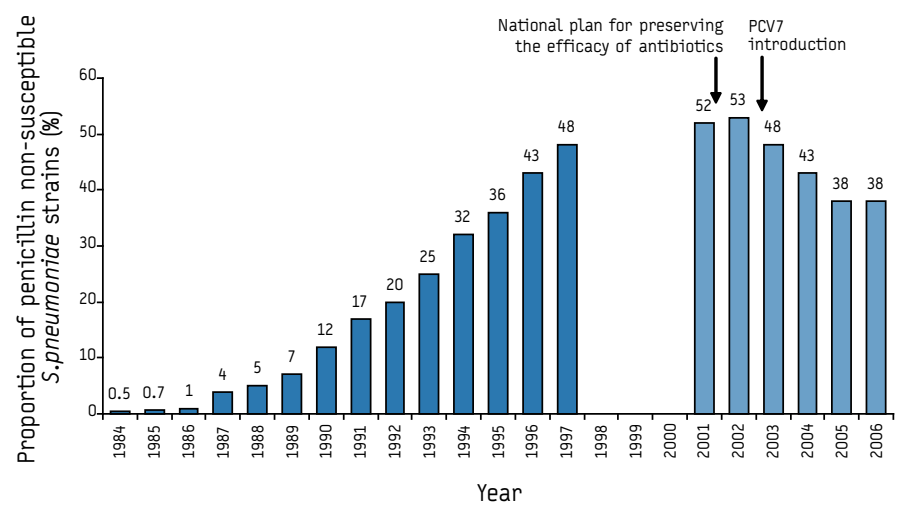

Note. no national figures from 1998 to 2000, as CNRP activities were interrupted. CNRP: national reference centre for S. pneumoniae; PCV7: 7-valent pneumococcal protein conjugate vaccine. promoted prudent use of antibiotics. The campaign has been repeated every winter since 2002 and become widely known and popular, parents becoming more and more aware of the benefits and limits of antibiotics [6].

Other interventions since 2002 have been aimed at general practitioners, including academic detailing, peer-to-peer visits by health insurance delegates and the promotion of the streptococcal group $A$ rapid diagnostic test for sore throat, that CNAMTS distributed to physicians free of charge. Data sent to the European surveillance of antimicrobial consumption (ESAC) network by the French Health Product Safety Agency (Afssaps) show that the overall antimicrobial consumption in ambulatory care in France has decreased from 33.0 defined daily doses per 1,000 inhabitants per day in 2001 to 27.9 in 2006, a reduction of $15 \%$; the consumption of broad-spectrum penicillins (ATC4 code J01CA) has decreased by $20 \%$ and the consumption of macrolides (ATC4 code J01FA) by 39\% (http://www.esac.ua.ac.be/). CNAMTS later demonstrated that its campaign was cost-effective [7].

In addition to reduced consumption of antibiotics, the introduction in March 2002 of the 7-valent protein conjugate vaccine (PCV7) for children under the age of two years [8] is likely to have contributed to the larger and faster decrease of PNSP rates among this age group than among adults. In 2002, serotypes covered by PCV7 (4, 6B, 9V, 14, 18C, 19F and 23F) accounted for $71 \%$ of invasive pneumococcal disease in France; most of them (68\%) were PNSP, as compared to $44 \%$ for nonvaccine serotypes [4]. From 2004 to 2007, PCV7 vaccine coverage increased from $27 \%$ in six-month-old children to $56 \%$ in six- to 12-month-old children $[9,10]$. In children under the age of two years, the incidence between 2001/02 and 2006 of pneumococcal meningitis and bacteraemia decreased from 8.0 to 6.0 and from 21.8 to 17.5 cases per 100,000 , respectively [11].

A partial replacement of vaccine serotypes by non-vaccine serotypes such as 19A, a serotype with a proportion of $85 \%$ PNSP in 2006, may explain why the decrease in the proportion of PNSP was not sustained in 2006 [12].

T A B L E 1

Proportion of penicillin non-susceptible $S$. pneumoniae among invasive isolates, by age and type of isolate, France, 2001 to 2006

\begin{tabular}{|c|c|c|c|c|c|c|c|c|c|c|c|c|}
\hline & \multicolumn{2}{|c|}{2001} & \multicolumn{2}{|c|}{2002} & \multicolumn{2}{|c|}{2003} & \multicolumn{2}{|c|}{2004} & \multicolumn{2}{|c|}{2005} & \multicolumn{2}{|c|}{2006} \\
\hline & N & $\%$ & N & $\%$ & N & $\%$ & $\mathrm{~N}$ & $\%$ & N & $\%$ & N & $\%$ \\
\hline \multicolumn{13}{|l|}{ Children } \\
\hline \multicolumn{13}{|l|}{$<2$ years } \\
\hline Blood isolates & 143 & 62.2 & 104 & 59.6 & 170 & 58.8 & 83 & 39.8 & 145 & 41.4 & 99 & 46.5 \\
\hline CSF isolates & 87 & 66.7 & 69 & 62.3 & 99 & 44.4 & 72 & 50.0 & 76 & 39.5 & 67 & 26.9 \\
\hline \multicolumn{13}{|l|}{ 2-15 years } \\
\hline Blood isolates & 150 & 30.7 & 87 & 37.9 & 183 & 33.9 & 123 & 31.7 & 206 & 23.8 & 133 & 23.3 \\
\hline CSF isolates & 39 & 51.3 & 37 & 37.8 & 37 & 35.1 & 41 & 29.3 & 55 & 30.9 & 33 & 30.3 \\
\hline All isolates from children & 419 & 50.8 & 297 & 51.2 & 489 & 44.8 & 319 & 37.6 & 482 & 32.4 & 332 & 31.6 \\
\hline \multicolumn{13}{|l|}{ Adults (>15 years) } \\
\hline Blood isolates & 828 & 46.0 & 678 & 46.0 & 635 & 41.6 & 232 & 44.8 & 461 & 36.2 & 308 & 34.1 \\
\hline CSF isolates & 213 & 42.3 & 214 & 42.3 & 255 & 42.4 & 209 & 38.3 & 294 & 36.1 & 215 & 36.3 \\
\hline All isolates from adults & 1,041 & 45.2 & 892 & 45.2 & 890 & 41.8 & 441 & 41.7 & 755 & 36.2 & 523 & 35.0 \\
\hline Total & 1,460 & 46.8 & 1,189 & 47.5 & 1,379 & 42.9 & 760 & 40.0 & 1,237 & 34.7 & $855^{1}$ & 33.7 \\
\hline
\end{tabular}

1 age missing for two of the 857 strains reported in 2006 .

$\mathrm{N}$ : strains tested for susceptibility; \%: proportion of PNSP among tested strains. 


\section{Stophylococcus oureus resistance trends}

\section{Data sources}

Data on methicillin resistance among $S$. aureus strains are issued from four different sources; all involved laboratories follow the recommendations from the Antibiogram Committee of the French Society for Microbiology (CA-SFM, http://www.sfm.asso. $\mathrm{fr} /$ ) for antimicrobial susceptibility testing and breakpoints.

The first source is the data submitted each year since 2001 by France to EARSS (http://www.rivm.nl/earss/), collected by three microbiological networks that contribute to the "Observatoire national de l'épidémiologie de la résistance bactérienne aux antibiotiques" (Onerba). They include 19 teaching hospitals of the Azay-Resistance network, nine general hospitals of the lle-deFrance network, and, since 2004, 26 hospitals, mostly general hospitals, of the Reussir network (http://www.onerba.org/). These data allow calculating the proportion of methicillin-resistant $S$. aureus (MRSA) isolates among all $S$. aureus invasive isolates.

The second source is the national multidrug-resistant bacteria surveillance network (BMR-Raisin, http://www.invs.sante.fr/raisin/), which includes the five interregional infection control coordinating centres (CClin) and has been collecting data on MRSA isolates from all diagnostic specimens (excluding screening isolates) since 2002. More than 450 microbiological laboratories participate on a voluntary basis each year (between 478 in 2002 and 675 in 2006, when it accounted for $47 \%$ of all French hospital beds), making it possible to calculate the incidence density of MRSA infections in healthcare facilities per 1,000 patient days (pd) [13].

The third source is national prevalence surveys on nosocomial infections, which have been conducted every five years in French healthcare facilities since 1996 . Antibiotic susceptibility profiles are recorded for selected pathogens (including $S$. aureus) that are recovered from any nosocomial infection, thus providing a measure of the prevalence of patients infected with MRSA [14].

The fourth and last source is a network of 39 teaching hospitals in the Paris area belonging to a single organisation, the "Assistance publique - Hôpitaux de Paris" (AP-HP); MRSA surveillance started there in 1993 and provides the longest continuous time series available on this topic in France.

\section{Results}

According to the latest EARSS report [15], France remained in 2006 one of the European countries with the highest proportion of MRSA among $S$. aureus isolates. However, while MRSA rates in most countries were increasing in 2006 (including those with the lowest rates), the report highlighted decreasing rates in two countries: France and Slovenia. In France, the MRSA proportion has decreased from $33 \%$ in 2001 to $26 \%$ in 2007 . The additional 26 French laboratories enrolled in the EARSS data collection since 2004 actually slowed this downward trend, as they accounted for $38 \%$ of all S. aureus strains in 2006 and their MRSA proportions were higher than in other participating laboratories (Table 2).

The decreasing proportion of MRSA among $S$. aureus, as reported by EARSS, is confirmed by national incidence data collected through the BMR-Raisin network. Data from 227 laboratories that have participated in this network since 2003 (totalling more than $4,000,000$ pd each year) point to a decreasing incidence density of MRSA infections in acute care wards, which fell from 0.89 MRSA infections per 1,000 pd in 2003 to 0.64 MRSA infections per $1,000 \mathrm{pd}$ in 2007 . This trend was even more pronounced in intensive care units, where the incidence density fell from 2.37 MRSA infections per 1,000 pd in 2003 to 1.59 MRSA infections per 1,000 pd in 2007 (Figure 2) [Raisin, unpublished data].

A decrease in MRSA rates was also noted in national prevalence surveys, through comparison of data from the 1,351 healthcare facilities having contributed to the surveys in 2001 and 2006 which included 550,637 patients $(279,490$ patients in 2001 and 271,147 in 2006). In these 1,351 healthcare facilities, the proportion of nosocomial infections with a microbiological diagnosis increased from $72 \%$ in 2001 to $78 \%$ in 2006 , as did the proportion of $S$. aureus strains tested for antimicrobial susceptibility $(93 \%$ in 2001 and $96 \%$ in 2006). The proportion of MRSA among S. aureus isolates decreased from $62 \%$ in 2001 to $50 \%$ in 2006 . The prevalence of MRSA-infected patients decreased from $0.49 \%$ in 2001 to $0.29 \%$ in 2006 , a reduction of $41 \%$. This trend was
T A B L E 2

Proportion of methicillin-resistant $S$. aureus among strains isolated from invasive isolates, by network contributing to EARSS, France, 2001 to 2007

\begin{tabular}{|c|c|c|c|c|c|c|c|c|}
\hline \multirow{2}{*}{ Year } & \multicolumn{2}{|c|}{$\begin{array}{c}\text { Azay- } \\
\text { Resistance }\end{array}$} & \multicolumn{2}{c|}{ Ile-de-France } & \multicolumn{2}{c|}{ Reussir } & \multicolumn{2}{|c|}{ Total } \\
\cline { 2 - 9 } & N & $\%$ & N & $\%$ & N & $\%$ & N & $\%$ \\
\hline 2001 & 1,459 & 32.8 & 248 & 35.5 & - & - & 1,707 & 33.2 \\
\hline 2002 & 1,425 & 32.9 & 238 & 33.2 & - & - & 1,663 & 32.9 \\
\hline 2003 & 1,419 & 28.3 & 285 & 31.9 & - & - & 1,704 & 28.9 \\
\hline 2004 & 1,596 & 26.4 & 319 & 28.2 & 1,409 & 31.6 & 3,324 & 28.8 \\
\hline 2005 & 1,905 & 24.9 & 204 & 30.9 & 1,343 & 29.9 & 3,452 & 27.2 \\
\hline 2006 & 2,078 & 25.7 & 276 & 25.0 & 1,444 & 28.4 & 3,798 & 26.7 \\
\hline $2007^{*}$ & 2,429 & 25.3 & 287 & 20.2 & 1,535 & 27.7 & 4,251 & 25.7 \\
\hline
\end{tabular}

*preliminary data as of July 2008 ;

$\mathrm{N}$ : strains tested for susceptibility; \%: proportion of MRSA among tested strains; EARSS: European Antimicrobial Resistance Surveillance System; MRSA methicillin-resistant S. aureus;

\section{F I G U R E 2}

Methicillin-resistant $S$. aureus incidence density in healthcare facilities that have participated since 2003 in the BMR-Raisin Network, by type of unit, France, 2003 to $2007(n=227)$

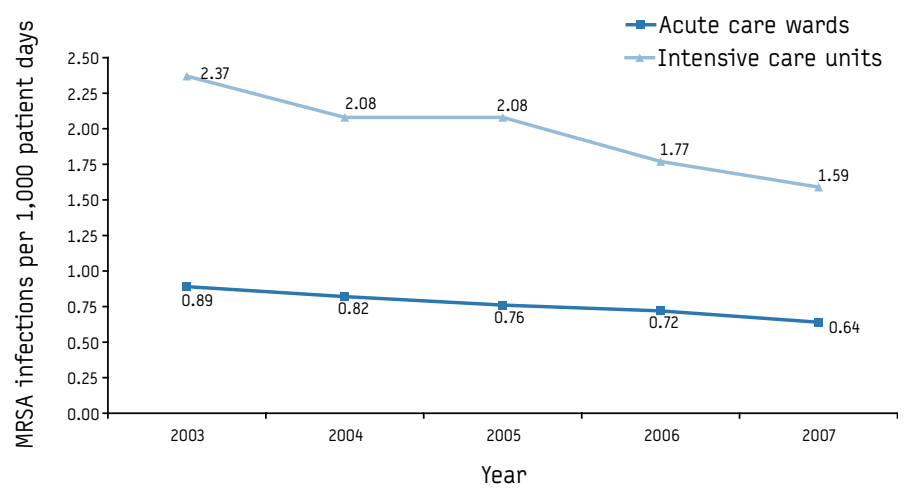

MRSA: methicillin-resistant S. aureus. 
observed across all types of healthcare facility, from university hospitals to long-term care facilities, and across all subspecialties but obstetrics (Table 3); it remained significant after adjusting for the patients' case-mix in a multivariate analysis [14].

Finally, in the AP-HP group, the proportion of MRSA among $S$. aureus isolated from clinical specimens in acute care decreased from $39 \%$ in 1993 to $22 \%$ in 2007 . At the same time, the incidence density of MRSA decreased from 1.16 MRSA infections per 1,000 pd in 1996 to 0.57 MRSA infections per 1,000 pd in 2007 (Figure 3) [AP-HP, unpublished data].

\section{F I G U R E 3}

MRSA proportion among S. aureus, and MRSA incidence, 39 teaching hospitals of the Paris area, 1993 to 2007

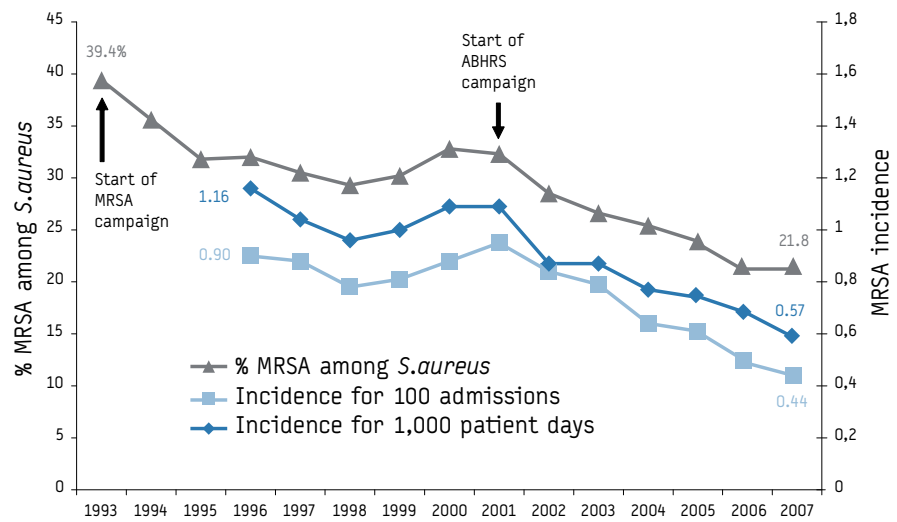

Year

Source: Assistance publique - Hôpitaux de Paris

MRSA: methicillin-resistant S. aureus. ABHRS: alcohol-based hand rub solutions

\section{Discussion: prevention and control activities}

Interventions that may account for the decrease in MRSA rates in France started in 1992, when the first European study on MRSA reported that the proportion of MRSA among $S$. aureus was $33.8 \%$ in France, the second highest proportion after Italy [16]. In 1995, a first multicenter survey in 43 hospitals showed that the median MRSA incidence in French intensive care units was 2.82 MRSA infections per 1,000 pd [17]. At that time, infection control teams were progressively implemented in French healthcare facilities, CClin had just been created, and antimicrobial resistance surveillance networks were being developed. A group of French intensive care specialists and microbiologists decided to start acting first in their own hospitals within the AP-HP group, and produced in 1993 (Figure 3) the first recommendations for prevention and control of multidrug-resistant bacteria [18].

The AP-HP recommendations provided the basis for the first national guidelines issued in 1999 by the French Ministry of Health and its Hospital Infection Control Advisory Committee [19]. They were disseminated to healthcare facilities and services through the CClin who coordinate regional networks of infection control teams and targeted diagnosis of multidrug-resistant bacteria, contact precautions, reinforcement of hand hygiene, isolation and cohorting, screening of patients, prudent antimicrobial use and evaluation through audits of practices and surveillance.

Interestingly, the fact that it is still necessary nowadays to include these key targets into national plans, shows that the fight against antimicrobial resistance is a long road. In addition, it takes time to provide the resources for adequate infection control nationwide - in 2006, 92\% of French healthcare facilities had an infection control team, according to a yearly survey performed by the Ministry of Health [20] - and to integrate recommendations in the daily clinical practice - in 2001, a study assessing the implementation of recommendations in 395 French intensive care units found that $70 \%$ performed active surveillance cultures for MRSA and that $88 \%$ flagged and isolated carriers [21]. Even if there is still room for improvement, the situation appeared to be considerably better than the one in the United States, a country with very high MRSA

T A B L E 3

Prevalence of methicillin-resistant $S$. aureus infected patients, by type of ward and year of survey; French national prevalence surveys, 2001 and 2006

\begin{tabular}{|c|c|c|c|c|c|c|c|}
\hline \multirow{3}{*}{ Specialty } & \multicolumn{3}{|c|}{2001} & \multicolumn{3}{|c|}{2006} & \multirow{3}{*}{$\underset{(\%)}{\Delta}$} \\
\hline & \multirow{2}{*}{$\frac{\text { Patients }}{\mathrm{N}}$} & \multicolumn{2}{|c|}{ Infected } & \multirow{2}{*}{$\frac{\text { Patients }}{\mathrm{N}}$} & \multicolumn{2}{|c|}{ Infected } & \\
\hline & & N & $\%$ & & N & $\%$ & \\
\hline Acute care & 146,445 & 708 & 0.48 & 147,908 & 437 & 0.30 & -39 \\
\hline - medicine & 72,933 & 325 & 0.45 & 76,418 & 212 & 0.28 & -38 \\
\hline - surgery & 49,086 & 253 & 0.52 & 47,776 & 148 & 0.31 & -40 \\
\hline - obstetrics & 18,313 & 6 & 0.03 & 18,356 & 10 & 0.05 & \\
\hline - intensive care & 6,113 & 124 & 2.03 & 5,358 & 67 & 1.25 & -38 \\
\hline Rehabilitation & 42,737 & 331 & 0.77 & 43,203 & 173 & 0.40 & -48 \\
\hline Long term care & 55,370 & 295 & 0.53 & 44,720 & 161 & 0.36 & -32 \\
\hline Psychiatry & 34,867 & 24 & 0.07 & 33,791 & 8 & 0.02 & -66 \\
\hline Other & 71 & 2 & 2.82 & 1,525 & 2 & 0.13 & \\
\hline Total & 279,490 & 1360 & 0.49 & 271,147 & 781 & 0.29 & -41 \\
\hline
\end{tabular}

Note: This analysis was restricted to nosocomial infections acquired in the 1,351 healthcare facilities that participated in both surveys.

$\Delta(\%)=$ relative difference in prevalence between 2006 and 2001 
rates, where only $18 \%$ of hospitals performed MRSA surveillance cultures in high risk units in 2003 [22].

More recently, MRSA control in France has been reinforced through the extensive promotion and use of alcohol-based hand rub solutions for hand hygiene. An intensive campaign to promote their use was launched within the AP-HP group (Figure 3), and the overall usage increased from 1 to 21 litres per $1,000 \mathrm{pd}$ from 2000 to 2007 [AP-HP, unpublished data]. Similar campaigns were conducted in other hospitals and regions, e.g. in Western France where a survey recently reported that the usage of alcohol-based hand rub solutions has doubled in the period from 2002 to 2005 [23].

Other factors that possibly contributed to the decrease of MRSA in France may have been the strong and coordinated national infection control programme that allocates infection control resources and sets quantitative objectives through indicators, as well as patients' associations asking for more results and transparency. The benefits and pitfalls of public reporting of infection control indicators remain a matter of debate. Such indicators have been progressively implemented in France since 2006 by the Ministry of Health (http://www.icalin.sante.gouv.fr/). They include scores that rate nosocomial infection control organisation and activities in each hospital (ICALIN) and the overall consumption of alcoholbased hand rub products (ICSHA) [24]. Our experience suggests that they provide a strong incentive for healthcare facilities to develop infection control activities and may be a key element for a sustainable decrease in MRSA rates.

\section{Conclusion}

PNSP and MRSA rates remain very high in France compared to Northern Europe countries [15]. Although the recent trends are encouraging, it is difficult to relate them to specific actions, as the interventions were multifaceted and implemented simultaneously. However, they suggest that the prevention efforts implemented since 2000 were successful and the national targets set in 2004 for 2008 will hopefully be reached.

According to a modelling study published in 2006, it may take more than 10 years to lower MRSA rates in countries with high prevalence [25]. The trends observed in France confirm that the fight against antimicrobial resistance is a long and demanding challenge and suggest that the dissemination of recommendations for a rational use of antibiotics, infection control and vaccination should be actively pursued.

* Data on other multidrug-resistant bacteria in France are available through the InVS website at http://www.invs.sante.fr/ratb/ (French and English versions).

\section{Acknowledgments}

For their contribution to these results, we thank the French microbiological laboratories, infection control teams, healthcare facilities, healthcare professionals and institutions involved in antimicrobial resistance surveillance, infection control and antibiotic stewardship.
Contributors in alphabetical order:

JM Azanowsky ${ }^{1}$, C Brun-Buisson ${ }^{2}$, A Carbonne ${ }^{3}$, P Cavalié ${ }^{4}$, B Coignard ${ }^{3,5}$, T Demerens ${ }^{6}$, JC Desenclos ${ }^{5}$, D Guillemot ${ }^{7}$, L Gutmann ${ }^{8}$, V Jarlier ${ }^{3,9}$, A Lepoutre ${ }^{5}$, D Levy-Bruhl ${ }^{5}$, S Maugat ${ }^{3,5}$ L May-Michelangeli², P Parneix ${ }^{3}$, B Schlemmer ${ }^{1}$, JM Thiolet ${ }^{3,5}$, E Varon ${ }^{8}$

1. Plan national pour préserver l'efficacité des antibiotiques (French national plan for preserving the efficacy of antibiotics), Health Ministry, Paris, France

2. Programme national de lutte contre les infections nosocomiales (French national infection control programme), Health Ministry, Paris, France

3. Réseau d'alerte, d'investigation et de surveillance des infections nosocomiales (Raisin, National nosocomial infection alert, investigation and surveillance network), Saint-Maurice, France

4. Agence française de sécurité sanitaire des produits de santé (Afssaps, French health products safety agency), Saint-Denis, France

5. Institut de veille Sanitaire (InVS, French institute for public health surveillance), Saint-Maurice, France

6. Caisse nationale d'assurance maladie des travailleurs salariés (CNAMTS, French National Insurance Fund for Salaried Workers), Paris, France

7. Institut Pasteur, Paris, France

8. Centre national de référence des pneumocoques (CNRP, French national reference centre for pneumococci), Paris, France

9. Observatoire national de l'épidémiologie de la résistance bactérienne aux antibiotiques (Onerba, French national observatory for epidemiology of the bacterial resistance to antimicrobials), Paris, France

\section{References}

1. French Ministry of Health. [2007-2010 national plan to preserve the efficacy of antibiotics]. [In French]. Paris: Ministère de la Santé; 2007. Available from: http://www.sante.gouv.fr/htm/dossiers/plan_antibio_2001/sommaire.htm

2. French Ministry of Health. [2005-2008 national infection control programme ]. [In French]. Paris: Ministère de la santé; 2004. Available from: http://www. sante.gouv.fr/htm/actu/infect_nosoco181104/prog.pdf

3. French Ministry of Health. [Circular nDGS/SD1C/2005/123 regarding the introduction of dispositions 88 to 96 of the law regarding public health policy]. [In French]. Paris: Ministère de la santé; 2005. Available from: http:// www.sante.gouv.fr/htm/dossiers/biomedicale_circulaire/05_123t0.pdf

4. Varon E, Gutmann L. [National reference centre for pneumococci; 2007 activities report, 2006 epidemiology]. [In French]. Paris: Centre National de Référence des Pneumocoques; 2007. Available from: http://www.invs.sante. fr/surveillance/cnr/rapport_cnr_pneumo_2007.pdf

5. Guillemot D, Varon E, Bernede C, Weber P, Henriet L, Simon S, et al. Reduction of antibiotic use in the community reduces the rate of colonization with penicillin G-nonsusceptible Streptococcus pneumoniae. Clin Infect Dis. 2005;41(7):930-8.

6. Goossens H, Guillemot D, Ferech M, Schlemmer B, Costers M, van Breda M, et al. National campaigns to improve antibiotic use. Eur J Clin Pharmacol. 2006;62(5):373-9.

7. Inspection générale des affaires sociales (IGAS). [Knowledge of general practitioners on medication]. [In French].,Report n'RM 2007-136P. Paris: IGAS; 2007. p. 226. Available from : http://lesrapports.ladocumentationfrancaise.fr/ BRP/074000703/0000.pdf

8. Pebody RG, Leino T, Nohynek H, Hellenbrand W, Salmaso S, Ruutu P. Pneumococcal vaccination policy in Europe. Euro Surveill. 2005;10(9):pii=564. Available from: http://www.eurosurveillance.org/ViewArticle. aspx?ArticleId=564

9. Cohen R, Gaudelus J, Pexoito 0 . [Anti-pneumococcal conjugate vaccine: estimation of the target population. Survey with 1739 mothers. [In French] Médecine et Enfance. 2005;25(4):237-42.

10. Gaudelus J, Cohen R, Hovart J. [Vaccine coverage with the heptavalent pneumococcal conjugate vaccine in 2007. Comparison with previous years and other paediatric vaccines: analysis of vaccination booklets]. [In French]. Médecine et Enfance. 2007;27(5):1-4.

11. Lepoutre A, Varon E, Georges S, Gutmann L, Levy-Bruhl D. Impact of infant pneumococcal vaccination on invasive pneumococcal diseases in France, 2001-2006. Euro Surveill. 2008;13. Euro Surveill. 2008;13(35):pii=18962. Available from: http://www.eurosurveillance.org/ViewArticle.aspx?ArticleId=18962

12. Kyaw MH, Lynfield R, Schaffner W, Craig AS, Hadler J, Reingold A, et al. Effect of introduction of the pneumococcal conjugate vaccine on drug-resistant Streptococcus pneumoniae. N Engl J Med. 354(14):1455-63.

13. Carbonne A, Arnaud I, Coignard B, Trystram D, Marty N, Maugat S, et al. Multidrug-resistant bacteria surveillance, France, 2002-2005. 17th European Congress of Clinical Microbiology and Infectious Diseases; 2007 March 31-April 3; Munich, Germany. 2007. [Abstract \#0364]. 
14. Thiolet JM, Lacavé L, Jarno P, Metzger MH, Tronel H, Gautier C, et al. [Prevalence of nosocomial infections France, 2006]. [In French]. Bull Epidemiol Hebd. 2007;51-52:429-32. Available from: http://www.invs.sante.fr/beh/2007/51 52/ beh_51_52_2007.pdf

15. European Antimicrobial resistance surveillance system (EARSS). 2006 annual report. Bilthoven: EARSS; 2007. Available from: http://www.rivm.nl/earss/ Images/EARSS\%202006\%20Def_tcm61-44176.pdf

16. Voss A, Milatovic D, Wallrauch-Schwarz C, Rosdahl VT, Braveny I. Methicillinresistant Staphylococcus aureus in Europe. Eur J Clin Microbiol Infect Dis. 1994;13(1):50-5.

17. The Hôpital Propre II Study Group. Methicillin-resistant Staphylococcus aureus in French hospitals: a 2-month survey in 43 hospitals, 1995. Infect Control Hosp Epidemiol. 1999;20(7):478-86.

18. Assistance Publique-Hôpitaux de Paris. [Control of the spread of multidrugresistant bacteria in hospitals]. [In French]. Paris: Service Etude, Hygiène et Prévention de l'Assistance Publique-Hôpitaux de Paris; 1993.

19. French Ministry of Health, Technical Committee for nosocomial infections. [Control of the spread of multidrug-resistant bacteria]. [In French]. Paris: Ministère de la santé;.1999. Available from: www.sante.gouv.fr/htm/pointsur/ nosoco/bacteries/maitbact.html

20. May-Michelangeli L, Drouvot V, Garnier P, Salomon V. National infection control policy : how far are infection control teams in 2006? XIXème Congrès national de la SFHH; 2008 June 5-6; , Paris, France. [Abstract P-082]. Available from: http://www.sfhh.net/telechargement/paris/posters_textes.pdf

21. L'Hériteau F, Alberti C, Cohen Y, Troché G, Moine P, Timsit JF. Nosocomial infection and multidrug-resistant bacteria surveillance in intensive care units: a survey in France. Infect Control Hosp Epidemiol. 2005;26(1):13-20.

22. Sunenshine RH, Liedtke LA, Fridkin SK, Strausbaugh LJ, the IDSA Network Management of inpatients colonized or infected with antimicrobial resistant bacteria in hospitals in the United States. Infect Control Hosp Epidemiol. 2005;26(2):138-43.

23. Centre de coordination de la lutte contre les infections nosocomiales (CClin) Ouest. [Usage of hand hygiene products]. [In French]. Nosonews 2007;(41):7-8. Available from: http://www.cclinouest.com/PDF/news41.pdf

24. Parneix P, Salomon V, Garnier P, Drouvot V, Tran B. [French nosocomial infection control indicators for public reporting]. [In French]. Bull Epidemiol Hebd. 2007;12-13:102-4. Available from: http://www.invs.sante.fr/beh/2007/12_13/ beh_12_13_2007.pdf

25. Bootsma MC, Diekmann 0, Bonten MJ. Controlling methicillin-resistant Staphylococcus aureus: quantifying the effects of interventions and rapid diagnostic testing. Proc Natl Acad Sci U S A. 2006;103(14):5620-5.

This article was published on 13 November 2008.

Citation style for this article: Anonymous. Recent trends in antimicrobial resistance among Streptococcus pneumoniae and Staphylococcus aureus isolates: the French experience. Euro Surveill. 2008;13(46):pii=19035. Available online: http://www. eurosurveillance.org/ViewArticle.aspx?ArticleId=19035 